\title{
Assessing sleep quality of Lebanese high school students in relation to lifestyle: pilot study in Beirut
}

\author{
Ramez Chahine, ${ }^{1}$ Rita Farah, ${ }^{2}$ Michèle Chahoud, ${ }^{3}$ Alain Harb, ${ }^{1}$ Rami Tarabay, ${ }^{1}$ Eric Sauleau ${ }^{4}$ and Roger Godbout 5
}

${ }^{1}$ Faculty of Health, La Sagesse University, Beirut, Lebanon (Correspondence to: R. Chahine: ramez.chahine@uls.edu.lb; charamez@hotmail.com). ${ }^{2}$ Faculty of Pharmacy, Lebanese University, Hadath, Beirut, Lebanon. ${ }^{3}$ Doctoral School of Science and Technology, Lebanese University, Hadath, Beirut, Lebanon. ${ }^{4}$ Laboratoire ICube, Laboratoire des sciences de l'ingénieur, de l'informatique et de l'imagerie (CNRS, UMR7357), Université de Strasbourg, France. ${ }^{5}$ Laboratoire et clinique du sommeil, Hôpital Rivière-des-Prairies, Université de Montréal, Québec, Canada.

\begin{abstract}
Background: Sleep problems in teenagers seriously disturb the active process of learning. Given the absence of sleep data from Lebanon, a study to determine sleep quality among adolescents is vital.

Aims: To understand sleep habits and patterns that affect sleep quality, and assess the amplitude of possible sleep problems in Lebanese adolescents, raising awareness of the effects of good sleep hygiene on general health in adolescents.

Methods: A cross-sectional survey of 500 high-school students in Beirut was conducted using a self-filled questionnaire inquiring about sociodemographics, health-risk behaviour and sleep quality. The effect of several factors related to sleep habits of the students was investigated using bivariate analysis and logistic regression.

Results: We found that $76.5 \%$ of teenagers were not satisfied with their sleep quality; $56 \%$ did not have the appropriate amount of sleep (<8 hours); and 82.4\% used mobile phones and electronic devices in bed before falling asleep. Moreover, 3.2\% faced a real problem with sleep initiation, $11.3 \%$ with sleep maintenance and $8.7 \%$ with early awakening.

Conclusions: A large proportion of high-school students in Beirut have poor sleep patterns. It is therefore necessary to increase awareness of the problem in education in order to prevent its escalation.

Keywords: adolescence, Lebanon, lifestyle, sleep hygiene, sleep wake disorders
\end{abstract}

Citation: Chahine R; Farah R; Chahoud M; Harb A; Tarabay R; Sauleau E, et al. Assessing sleep quality of Lebanese high school students in relation to lifestyle: pilot study in Beirut. East Mediterr Health J. 2018;24(8):722-728. https://doi.org/10.26719/2018.24.8.722

Received: 08/01/17; accepted: 31/07/17

Copyright (c) World Health Organization (WHO) 2018. Some rights reserved. This work is available under the CC BY-NC-SA 3.0 IGO license (https:// creativecommons.org/licenses/by-nc-sa/3.o/igo).

\section{Introduction}

Sleep is one of the vital body functions, along with breathing, digestion and immunity. It brings rest and regenerates the mind and body, enabling us to function optimally the next day. Sleep is not only a factor in good health, but it also affects the quality and rapidity of learning (1). Yet, we do not know its impact nor give it the importance it deserves.

Sleep disorders and deprivation are currently a major health problem, both in terms of frequency and social and economic impacts (2-4). Detection of sleep disorders in adults complaining of insomnia is a daily challenge for physicians and patients alike (5). Detection of sleep disorders in adolescents is even more difficult because they can have two different etiologies. On the one hand, the sleep/wake rhythms evolve from the fetal period and develop in adolescence both in structure and duration (6). During puberty, the circadian rhythm (sleep/wake cycles) of teenagers becomes delayed, which is why most highschool students are more active and awake in the evening, go to bed late and like to sleep late (7). On the other hand, many external factors affecting lifestyle of adolescents interfere with their sleep cycles. Thus, technology use is emerging as a possible contributing factor to sleep disturbance in the 21st century (8).
In adults, the average sleep time is 7-8 hours, but for some heavy sleepers, who represent $\sim 10 \%$ of the population, 9 or 10 hours of sleep are required for them to feel satisfied during the day. In contrast, $5 \%$ of short sleepers need only 5-6 hours a night. Consequently, there is no ideal amount of sleep $(9,10)$. The only true test of whether sleep is sufficient is to feel satisfied during the day.

During adolescence, major tangible psychological and social changes occur; the sleep-wake rhythm changes and the night time sleep shortens: the average duration of sleep per night decreases from 10 hours at 11 years to 7.5 hours at 18 years (a loss of 1 hour of sleep every 3 years) (11). However, in an American study (12), the need for sleep did not seem to decrease at puberty (with an average of 9.2 hours per night), although there was a biological tendency for teenagers to fall asleep and wake up later than during childhood. This leads to a true sleep disorder called phase delay. The resulting lack of sleep could explain school failures, accidents and social disorders. The exact prevalence of delayed sleep phase is unknown at this time.

Lebanon has more cultural and demographic diversity compared to other Middle Eastern countries. Furthermore, over a small geographical area, Lebanon has undergone many cultural shifts (including changes 
in eating habits, use of stimulants and use of electronic devices) and socioeconomic changes that could have contributed to the diversity of information extracted from our study, making it unique in its findings and methodology. There have been several studies on sleep disorders among adolescents, especially in developed countries, but to the best of our knowledge there have been no such studies in the Middle East, including Lebanon. To fill this gap we launched a pilot study to understand sleep habits and patterns that affect sleep quality, and assess the amplitude of possible sleep problems in Lebanese adolescents, raising awareness of the effects of good sleep hygiene on general health in adolescents.

\section{Methods}

\section{Study design and procedures}

A cross-sectional study using a multistage cluster sample was conducted during the school year 2015-2016. As this was a pilot study, no sample size calculation was performed and a sample of 500 participants was considered. From the list of schools in the Greater Beirut Area, 20 public and private schools were selected using simple randomization. From the list of students aged 14-19 years, 25 participants per school were randomly selected. A self-administered questionnaire was used to ensure total anonymity of participants. Participation in the study was voluntary and included no material compensation. Young working adolescents not enrolled in school were not selected. We collected data during regular days of the semester, avoiding examination periods, which might have added new parameters not considered in the study.

The questionnaire was specially developed for the study and included several sections that were pilot tested on a sample of 30 students. Most schools had legal restrictions on distribution of questionnaires without the consent of the Ministry of Education, thus, we were not given permission to distribute questionnaires to students ourselves. We were permitted to delegate this responsibility to the biology teachers, who were trained by us to assist students to complete the questionnaire. The questionnaires were completed in class, collected and returned to us by the trained teacher in charge.

This study was approved by the Ethics in Research Committee of the Lebanese University. Informed consent was obtained from each school administration, which in turn obtained written informed consent from the parents of students who met the inclusion criteria. The purpose of the research, confidentiality of information and benefit to the population were explained to the participants verbally. Anonymity and confidentiality of all participants were guaranteed and maintained.

\section{Study materials}

The questionnaire consisted of 5 sections: (1) demographic characteristics of the population (e.g., age and sex); (2) sleep habits of adolescents (alarm clock, and number of sleeping hours during weekdays and weekends); (3) sleep problems (sleep initiation, sleep maintenance and early awakening before getting full amount of sleep); (4) quality of sleep (satisfaction and relaxation in the morning, nightmares, urge to sleep during the day, and missing morning classes); and (5) lifestyle of adolescents (consumption of coffee, tea, alcohol, energy drinks and hypnotics, as well as information concerning evening activities, exercise, employment and dinner time). The questionnaire was compiled from 2 standardized tests used for the diagnosis of sleep disorders by the European Sleep Center, and Sleep \& Vigilance Center of Hôtel-Dieu, both in Paris, France $(13,14)$. Originally in French, the questionnaire was translated into Arabic and then independently back-translated into French by 2 translators to verify the translation and resolve any inconsistencies.

\section{Sleep patterns definition}

Trouble in sleep initiation was defined as individuals taking > 30 minutes to fall asleep. Trouble in sleep maintenance was defined as individuals waking up every night. Early awakening was defined as individuals waking early without being able to sleep again almost every night.

\section{Statistical analysis}

The databases were transferred on a spreadsheet file from Windows Excel 2007. The data were analysed using SPSS version 17.0 (IBM Corporation, Armonk, NY, USA). The internal consistency (Cronbach's $\alpha$ reliability) was 0.70. We used means with standard deviations and counts with percentages to describe continuous and categorical variables, respectively. We used Pearson's $\chi^{2}$ test for categorical variables and Student's t test to compare means between 2 groups. In all analyses, $\mathrm{P}<0.05$ was considered significant. Two multivariable analyses were performed, using logistic regression models to investigate the influence of demographics, health-risk behaviour and teenagers' activities before sleeping on sleep maintenance and early awakening before getting the full amount of sleep, after adjustment for age and gender. Health-risk behaviour and teenagers' activities that were significantly associated with sleep patterns in the bivariate analysis were included in the multivariable models. Adjusted odds ratios and their 95\% confidence intervals were reported.

\section{Results}

\section{Demographic characteristics}

We surveyed 520 adolescents and 20 declined to answer the questionnaire. We included 500 teenagers ( $297 \mathrm{fe}$ male, 203 male) with a mean age of 16.0 (0.8) years.

\section{Sleep duration}

More adolescents went to sleep after 22:30 hours at weekends than during the week (Table 1). During the week, more adolescents woke before 06:30 hours and more slept for $<8$ hours, compared with the weekend.

\section{Sleep disturbance and quality}

Table 2 shows the numbers of adolescents who took $>30$ minutes to fall asleep, woke during most nights, woke 


\begin{tabular}{|c|c|c|c|}
\hline & $\begin{array}{c}\text { Sleeping after 22:30 h } \\
\mathrm{n}(\%)\end{array}$ & $\begin{array}{c}\text { Waking before 06:30 h } \\
\text { n (\%) }\end{array}$ & $\begin{array}{c}\text { Sleep duration }<8 \mathbf{~ h} \\
\mathbf{n}(\%)\end{array}$ \\
\hline WD & $289(57.9)$ & $274(54.8)$ & $280(56.0)$ \\
\hline WE & $410(82)$ & $20(4.0)$ & $70(14.0)$ \\
\hline
\end{tabular}

$\mathrm{WD}=$ weekdays; $\mathrm{WE}=$ weekends.

early most days, experienced nightmares, had no sleep satisfaction, often felt a need to sleep during the day, and were absent from morning classes.

\section{Consumption of stimulants}

Table 2 shows the consumption of tobacco, alcohol, soft drinks, energy drinks, tea and coffee in the evening prior to sleep. It also shows the time that the adolescents took their evening meal.

Seventeen $(3.4 \%)$ teenagers reported use of tobacco, whereas 18 (3.7\%) reported drinking alcohol. This survey allowed us to identify different types of stimulants that participants used frequently in the evening. The majority often consumed soft drinks $(n=306,61.2 \%)$, coffee $(n=192$, $38.2 \%)$, energy drinks $(n=168,33.6 \%)$ and tea $(n=68,13.0 \%)$. We noted also that $335(66.5 \%)$ teenagers ate their dinner between 19:00 and 21:00 hours, compared with only 39 (8\%) who eat dinner after 22:00 hours.

\section{Evening and bedtime activities}

We shed light on different aspects of adolescent behaviour that could be considered as predisposing factors for poor sleep by asking the participants about their evening and bedtime activities. The main activity of adolescents in the evening and at bedtime was unrestrained use of the Internet $(\mathrm{n}=300,60 \%)$. This was followed by mobile phone $(\mathrm{n}=72,14.4 \%)$, reading $(\mathrm{n}=39,7.8 \%)$, television $(\mathrm{n}$ $=37,7.4 \%)$, other activities $(\mathrm{n}=50,10 \%)$ and video games ( $\mathrm{n}=2,0.4 \%$ ).

\section{Predictors affecting sleep maintenance}

In multivariable analysis, trouble in sleep maintenance was significantly associated with reporting sleeping $<8$ hours during weekdays, experiencing nightmares sometimes, drinking coffee sometimes and often in the evening, and having any activity in bed before sleeping other than reading (Table 3). Reporting waking up satisfied in the morning was negatively associated with trouble in sleep maintenance.

\section{Predictive factors affecting early awakening}

In multivariable analysis, early awakening was associated with sometimes experiencing nightmares, often feeling a need to sleep during the day and having any activity in bed before sleeping other than reading (Table 4). Reporting waking up moderately and very relaxed compared to not at all was inversely associated with early awakening.

\begin{tabular}{|c|c|c|}
\hline Factors & Categorization & n (\%) \\
\hline Time taken to fall asleep & $>30 \mathrm{~min}$ & $16(3.2)$ \\
\hline Waking during the night & Almost every night & $183(36.6)$ \\
\hline Waking early without being able to sleep & Almost every day & $44(8.7)$ \\
\hline Sleep satisfaction & No & $382(76.5)$ \\
\hline Waking difficulty & Often & $91(18.2)$ \\
\hline Feeling need to sleep during the day & Often & $90(18.1)$ \\
\hline Absence during morning school classes & Often & $1(0.2)$ \\
\hline Nightmares & Often & $7(1.4)$ \\
\hline Use of Stimulants & Often & \\
\hline Tobacco & - & $17(3.4 \%)$ \\
\hline Alcohol & - & $18(3.7 \%)$ \\
\hline Soft drinks & - & $306(61.2 \%)$ \\
\hline Coffee & - & $192(38.2 \%)$ \\
\hline Energy drinks & - & $168(33.6 \%)$ \\
\hline Tea & - & $68(13.6 \%)$ \\
\hline Dinner time & Often & \\
\hline Between 19:00 and 21:00 & - & $335(66.5 \%)$ \\
\hline Between 21:00 and 22:00 & - & $81(16.3 \%)$ \\
\hline Later than 22:00 & - & $39(8 \%)$ \\
\hline
\end{tabular}




\begin{tabular}{|c|c|c|c|c|c|}
\hline Predictors & Coefficient & Standard error & Adjusted OR & $95 \% \mathrm{CI}$ & $\mathbf{P}$ \\
\hline Sleep $<8$ h during weekdays & 1.79 & 0.60 & 5.98 & $1.78-20.07$ & 0.004 \\
\hline Wake satisfied & -1.27 & 0.29 & 0.28 & $0.15-0.51$ & $<0.001$ \\
\hline \multicolumn{6}{|l|}{ Nightmares } \\
\hline Sometimes vs. Never & 1.29 & 0.29 & 3.62 & $1.98-6.63$ & $<0.001$ \\
\hline Often vs. Never & -0.33 & 0.95 & 0.72 & $0.11-4.77$ & 0.7 \\
\hline \multicolumn{6}{|l|}{ Coffee } \\
\hline Sometimes vs. Never & 0.67 & 0.30 & 1.95 & $1.05-3.62$ & 0.03 \\
\hline Often vs. Never & 1.61 & 0.38 & 5.00 & $2.35-10.65$ & $<0.001$ \\
\hline Activity in bed before sleep & 0.78 & 0.25 & 2.19 & $1.30-3.71$ & 0.003 \\
\hline
\end{tabular}

$C I=$ confidence interval; $O R=$ odds ratio.

\section{Discussion}

We found that $76.5 \%$ of teens surveyed were not satisfied with their sleep quality and 56\% did not have the appropriate amount of sleep ( $<8$ hours). The main predisposing factor was using mobile phones and electronic devices in bed before falling asleep. Moreover, $3.2 \%$ had a problem with sleep initiation, $11.3 \%$ with sleep maintenance and $8.7 \%$ with early awakening before getting the full amount of sleep. No significant differences were found between boys and girls. Taking stimulants, Internet activity and mobile phone use before sleep and late dinners seem to be the main factors that predispose to inadequate sleep.

We have identified studies from developed countries that show that frequency of sleep disorders was lower than in our study. In France, a survey conducted on 652 young people aged $13-19$ years reported that $35.7 \%$ exhibited persistent insomnia-type sleep disorders (40.2\% of girls and $31.6 \%$ of boys) (15). More recently, it has been reported that total sleep time decreased severely during adolescence (16).
According to a survey conducted at the national level in the United States of America by the National Sleep Foundation in 1997 (17), college students went to sleep between 21:00 and 22:00 hours, while high-school students went to sleep between 22:00 and 23:00 hours, although both groups arose around 06:30 hours. Thus, $40-45 \%$ of adolescents do not get enough sleep $(<8$ hours per night). The results also showed that sleep deprivation is predominantly important for adolescents in general and older adolescents in particular. As a consequence, daytime sleepiness is often observed and objective measures show that teenagers are really lacking sleep (18).

These results indicate that, although studies have been conducted in countries with different socioeconomic and cultural backgrounds, frequency of sleep disorders is similar. Sleep disorders in adolescence are a frequent yet insidious problem. In fact, 1 in 4 teenagers have insomnia. It has also been observed that adolescents are secretive about their sleeping problems and do not speak spontaneously to their parents, but also because they do

\begin{tabular}{|c|c|c|c|c|c|}
\hline Predictors & Coefficient & Standard error & Adjusted OR & $95 \% \mathrm{CI}$ & $\mathbf{P}$ \\
\hline Sleep $<8$ h during weekdays & 0.50 & 0.26 & 1.66 & $0.98-2.82$ & 0.06 \\
\hline Wake relaxed & & & & & $<0.001$ \\
\hline Little vs. Not at all & -0.71 & 0.54 & 0.49 & $0.17-1.39$ & 0.18 \\
\hline Moderate vs. Not at all & -1.43 & 0.53 & 0.24 & $0.08-0.70$ & 0.009 \\
\hline Very vs. Not at all & -1.27 & 0.58 & 0.28 & $0.09-0.95$ & 0.04 \\
\hline \multicolumn{6}{|l|}{ Nightmares } \\
\hline Sometimes vs. Never & 1.6 & 0.27 & 4.90 & $2.84-8.45$ & $<0.001$ \\
\hline Often vs. Never & 0.79 & 0.45 & 2.2 & $0.89-4.67$ & 0.5 \\
\hline \multicolumn{6}{|l|}{ Feeling need to sleep during the day } \\
\hline Sometimes vs. Never & 0.67 & 0.35 & 1.95 & $0.98-3.86$ & 0.54 \\
\hline Often vs. Never & 1.32 & 0.41 & 3.74 & $1.67-8.34$ & 0.01 \\
\hline Absence during morning classes & 0.92 & 0.38 & 2.50 & $1.17-5.34$ & 0.007 \\
\hline Activity in bed before sleep & 0.76 & 0.26 & 2.14 & $1.27-3.62$ & 0.004 \\
\hline
\end{tabular}

$C I=$ confidence interval; $O R=$ odds ratio. 
not perceive nightmares and difficulty falling asleep as disorders (19).

As we already mentioned, the presence of a phase delay in circadian rhythms induced significant deprivation of sleep that accumulated throughout the week in adolescents. In Lebanon, as elsewhere, most classes start in the morning (between 07:30 and 08:00 hours) at a time when the circadian rhythms of adolescents still promote sleep. This time difference is greater as adolescents continue to go to bed late driven by their biological rhythms and social activities.

Sleep deprivation also affects the learning ability of adolescents. A study by Crowley et al. in 2006 (20) on this issue showed a decrease in performance in tests assessing memory and mathematical calculation after a night of sleep deprivation. One full night after a sleepless night did not seem enough for a full recovery. These findings are supported by Wolfson et al. (21), who showed that adolescents with classes starting an hour later than another had better educational outcomes, which was associated with the students being less sleepy during the day and that they slept overnight. Shortened sleep duration ( $\sim 6$ hours per night for 1 week) in adolescents results in more daytime sleepiness, difficulty concentrating, cognitive deficits (organization, planning, and working memory) and problems in terms of impulse control, regulation of emotions and behavioural flexibility $(22,23)$.

To compensate for sleep deprivation during the week, it is common that teenagers arise a few hours later on days without school. This difference caused by school and work time is called social jetlag (24). However, it often happens that sleep is not fully recovered, since social incentives such as part-time work and going out with friends push them to sleep still later; sometimes up to $>2$ hours the day after the weekend compared to school days $(15,25)$.

We also have to keep in mind the impact of technology on adolescent lifestyle. It has been reported that $97 \%$ of adolescents have an electronic device in their room and that in the hour before bedtime, $76 \%$ are watching television, $40 \%$ talking on the phone, $44 \%$ surfing the Internet and $26 \%$ playing video games (17). Engaging in stimulating activities is unfavourable to the onset of sleep, and the lights projected by the screen contribute to maintaining wakefulness, thereby delaying melatonin secretion (26).

Finally, consumption of beverages (coffee, tea, energy drinks and cola) to keep awake is common among adolescents. A study by Bailly et al. in 2004 reported that $\sim 31 \%$ of teenagers drink $>2$ caffeinated beverages a day (15). Another American study by Calamaro et al. in 2008 showed that $11.2 \%$ of adolescents ingested $>400 \mathrm{~g}$ of caffeine per day, which is the equivalent of 4 cups of coffee (26).

Our study had some limitations. Our presence in schools during completion of the questionnaires was difficult. We therefore instructed the biology teachers to assist the participants in case some difficulties were encountered while completing the questionnaire. However, reporting and declaration biases wereinevitable, and some associations may seem counterintuitive. Furthermore, this was designed as a pilot study and therefore the sample chosen is not representative of the Lebanese population of adolescents and the conclusions cannot be generalized. Although questions on nightmares are part of all validated questionnaires dealing with sleep problems, we think that varying interpretations of nightmares might have been a source of bias in our study.

In conclusion, our pilot survey demonstrated that school duty and homework, as well as the modern lifestyle adopted by present-day adolescents, cause an important sleep deprivation problem, whose impact requires a significant multidimensional response. This type of problem is likely to become increasingly important, and the establishment of good sleep hygiene and education about the importance of a good night's sleep are necessary to improve adolescent sleep quality. A national study is warranted to assess further adolescents' sleep quality in Lebanon.

\section{Acknowledgements}

Thanks to Dr Najib Haddad for the English editing.

Funding: In part by Agence Universitaire de la Francophonie, Bureau Moyen Orient.

Competing interests: None declared.

\section{Évaluer la qualité du sommeil des élèves du secondaire au Liban en fonction de leur mode de vie : étude pilote à Beyrouth}

\section{Résumé}

Contexte : Les troubles du sommeil chez les adolescents perturbent gravement l'activité du processus d'apprentissage. Étant donné l'absence de données concernant le sommeil au Liban, il est essentiel de mener une étude sur la qualité du sommeil chez les adolescents.

Objectif : Comprendre les habitudes et les tendances qui perturbent la qualité du sommeil et évaluer l'importance des éventuels problèmes chez les adolescents libanais, alerter l'opinion sur les effets d'une bonne hygiène de sommeil sur l'état de santé général des adolescents. 
Méthodes : Une étude transversale a été conduite auprès de 500 élèves du secondaire à Beyrouth àl'aide d'un questionnaire d'auto-évaluation. Les thèmes recouvraient les caractéristiques sociodémographiques, les comportements à haut risque et la qualité du sommeil. Une analyse bivariée et la régression logistique ont été utilisées pour examiner l'effet que pouvaient avoir divers facteurs associés aux habitudes de sommeil.

Résultats : L'étude a révélé que $76,5 \%$ des adolescents n'étaient pas satisfaits de la qualité de leur sommeil, $56 \%$ ne dormant pas un nombre suffisant d'heures ( $<8$ heures) ; et que $82,4 \%$ utilisaient leur téléphone mobile ou des appareils électroniques dans leur lit avant de dormir. De plus, 3,2\% éprouvaient de réelles difficultés pour s'endormir, $11,3 \%$ au niveau du maintien du sommeil et $8,7 \%$ se réveillaient tôt.

Conclusion : Une grande partie des élèves du secondaire à Beyrouth présentent de mauvaises habitudes de sommeil. Il est donc nécessaire de sensibiliser davantage la population dans le cadre de l'enseignement afin d'éviter toute aggravation de ce problème.

$$
\begin{aligned}
& \text { تقييم جودة النوم لدى طلاب المدارس الثانوية اللبنانية وعلاقته بنمط الحياة: دراسة ارتيادية في بيروت }
\end{aligned}
$$



$$
\begin{aligned}
& \text { الخالاصة } \\
& \text { الخلفية: تسبب مشاكل النوم عند المرِاهقينٍ اضطر اباً خطيراً فئ عملية التعلم الفعَّالة. ونظراً لغياب البيانات الواردة من لبنان حول النوم، تعد دراسة } \\
& \text { تحديد جودة النوم بين المراهقين أمراً حيوياً. }
\end{aligned}
$$

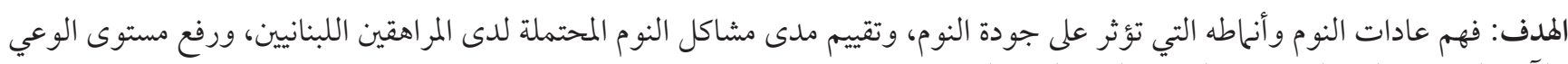

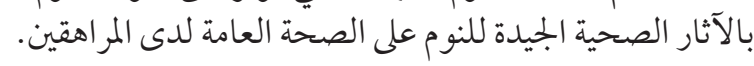





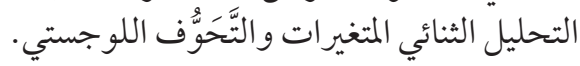





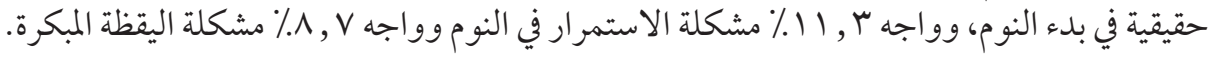



$$
\begin{aligned}
& \text { أجل منع تفاقمها. }
\end{aligned}
$$

\section{References}

1. Landmann N, Kuhn M, Piosczyk H, Feige B, Baglioni C, Spiegelhalder K, et al. The reorganisation of memory during sleep. Sleep Med Rev. 2014 Dec;18(6):531-41. https://doi.org/10.1016/j.smrv.2014.03.005 PMID:24813468

2. Wells ME, Vaughn BV. Poor sleep challenging the health of a nation. Neurodiagn J. 2012 Sep;52(3):233-49. PMID:23019761

3. Haapasalo-Pesu KM, Karukivi M. [Sleep disorders among adolescents - a major problem in mental health care]. Duodecim. 2012;128(22):2319-25 (in Finnish). PMID:23342478

4. Khazaie H, Chehri A, Sadeghi K, Heydarpour F, Soleimani A, Rezaei Z. Sleep hygiene pattern and behaviors and related factors among general population in west of Iran. Glob J Health Sci. 201608 1;8(8):53434. PMID:27045403

5. Ramar K, Olson EJ. Management of common sleep disorders. Am Fam Physician. 2013 Aug 15;88(4):231-8. PMID:23944726

6. MacLean JE, Fitzgerald DA, Waters KA. Developmental changes in sleep and breathing across infancy and childhood. Paediatr Respir Rev. 2015 Sep;16(4):276-84. PMID:26364005

7. Hagenauer MH, Perryman JI, Lee TM, Carskadon MA. Adolescent changes in the homeostatic and circadian regulation of sleep. Dev Neurosci. 2009;31(4):276-84. https://doi.org/10.1159/000216538 PMID:19546564

8. Gradisar M, Wolfson AR, Harvey AG, Hale L, Rosenberg R, Czeisler CA. The sleep and technology use of Americans: findings from the National Sleep Foundation's 2011 Sleep in America poll. J Clin Sleep Med. 2013 Dec 15;9(12):1291-9. PMID:24340291

9. Storfer-Isser A, Lebourgeois MK, Harsh J, Tompsett CJ, Redline S. Psychometric properties of the Adolescent Sleep Hygiene Scale. J Sleep Res. 2013 Dec;22(6):707-16. https://doi.org/10.1111/jsr.12059 PMID:23682620

10. Waterhouse J, Fukuda Y, Morita T. Daily rhythms of the sleep-wake cycle. J Physiol Anthropol. 2012 03 13;31(1):5. https://doi. org/10.1186/1880-6805-31-5 PMID:22738268

11. Laberge L, Petit D, Simard C, Vitaro F, Tremblay RE, Montplaisir J. Development of sleep patterns in early adolescence. J Sleep Res. 2001 Mar;10(1):59-67. https://doi.org/10.1046/j.1365-2869.2001.00242.x PMID:11285056 
12. Tarokh L, Raffray T, Van Reen E, Carskadon MA. Physiology of normal sleep in adolescents. Adolesc Med State Art Rev. 2010 Dec;21(3):401-17. PMID:21302851

13. Centre du sommeil et de la vigilance Hôtel-Dieu, Paris. Questionnaire des troubles du sommeil. www.sommeil-vigilance.fr

14. Gonçalves M, Amici R, Lucas R, Åkerstedt T, Cirignotta F, Horne J, et al. Sleepiness at the wheel across Europe: a survey of 19 countries. J Sleep Res. 2015; 24(3): 242-53.

15. Bailly D, Bailly-Lambin I, Querleu D, Beuscart R, Collinet C. [Sleep in adolescents and its disorders. A survey in schools]. Encephale. 2004 Jul-Aug;30(4):352-9 (in French). https://doi.org/10.1016/Soo13-7006(04)95447-4 PMID:15538310

16. Léger D, Beck F, Richard JB, Godeau E. Total sleep time severely drops during adolescence. PLoS One. 2012;7(10):e45204. https:// doi.org/10.1371/journal.pone.0045204 PMID:23082111

17. National Sleep Foundation. Adolescent sleep needs and patterns: research report and resource guide. Washington (DC): National Sleep Foundation; 2000.

18. Gibson ES, Powles AC, Thabane L, O’Brien S, Molnar DS, Trajanovic N, et al. "Sleepiness" is serious in adolescence: two surveys of 3235 Canadian students. BMC Public Health. 200605 2;6(1):116-24. https://doi.org/10.1186/1471-2458-6-116 PMID:16670019

19. Winterton PM. Child protection and the health professional: mandatory responding is our duty. Med J Aust. 2009 Sep 7;191(5):246-7. PMID:19740042

20. Crowley SJ, Acebo C, Carskadon MA. Sleep, circadian rhythms, and delayed phase in adolescence. Sleep Med. 2007 Sep;8(6):60212. https://doi.org/10.1016/j.sleep.2006.12.002 PMID:17383934

21. Wolfson AR, Spaulding NL, Dandrow C, Baroni EM. Middle school start times: the importance of a good night's sleep for young adolescents. Behav Sleep Med. 2007;5(3):194-209. https://doi.org/10.1080/15402000701263809 PMID:17680731

22. Beebe DW, Fallone G, Godiwala N, Flanigan M, Martin D, Schaffner L, et al. Feasibility and behavioral effects of an at-home multi-night sleep restriction protocol for adolescents. J Child Psychol Psychiatry. 2008 Sep;49(9):915-23. https://doi.org/10.1111/j.14697610.2008.01885.x PMID:18564072

23. Bériault M, Turgeon L, Labrosse M, Berthiaume C, Verreault M, Berthiaume C, et al. Comorbidity of ADHD and anxiety disorders in school-age children: impact on sleep and response to a cognitive-behavioral treatment. J Atten Disord. 2018 Mar;22(5):414-424. https://doi.org/10.1177/1087054715605914 PMID:26396144

24. Wittmann M, Dinich J, Merrow M, Roenneberg T. Social jetlag: misalignment of biological and social time. Chronobiol Int. 2006;23(1-2):497-509. https://doi.org/10.1080/07420520500545979 PMID:16687322

25. Fischer FM, Wey D, Valente D, Luz AA, Pinheiro F, Fonseca BC, et al. Sleep patterns and sleepiness among young students: a longitudinal study before and after admission as trainees and apprentices. Chronobiol Int. 2015; 32(4): 478-85. PMID:25541361

26. Calamaro CJ, Mason TB, Ratcliffe SJ. Adolescents living the 24/7 lifestyle: effects of caffeine and technology on sleep duration and daytime functioning. Pediatrics. 2009 Jun;123(6):e1005-10. https://doi.org/10.1542/peds.2008-3641 PMID:19482732 